\title{
O IMPACTO DAS NOVAS TECNOLOGIAS NOS DIREITOS HUMANOS E FUNDAMENTAIS: $O$ ACESSO À INTERNET E A LIBERDADE DE EXPRESSÃO
}

\section{The impact of new technologies in human and fundamental rights: internet access and freedom of speech}

\author{
GUILHERME DAMASIO GOULART \\ Mestrando em Direito Civil pela UFRGS. \\ Atua como advogado e consultor em Direito da Tecnologia e Segurança da Informação.
}

\section{RESUMO}

O presente trabalho trata sobre o impacto que as tecnologias de informação causaram nos direitos humanos e fundamentais. O foco principal é dado ao direito de acesso à Internet e à liberdade de expressão, ambos vistos e entendidos como direitos humanos fundamentais. A internet, neste contexto, é o ambiente principal de análise do problema. Destacase, com isto, o aparecimento dos chamados "direitos de quinta geração". O assunto é tratado por meio de análise doutrinária e normativa, destacando-se no último aspecto, a análise do Marco Civil da Internet no Brasil, das diretivas da União Europeia bem como da decisão do Conselho Constitucional Francês sobre a chamada lei Hadopi além de resoluções das Nações Unidas. Por fim, é afirmada a necessidade de proteção dos direitos fundamentais e humanos no ambiente digital e é considerada a utilização de normas de fontes comunitárias ou de tratados internacionais para a ampliação da proteção de tais direitos.

Palavras-chave: Direito; Direitos Humanos e Fundamentais; Internet; Liberdade de Expressão; Direito de Acesso à Internet

\begin{abstract}
This paper deals with the impact of information technologies have caused in human and fundamental rights. The main focus is given to the right of Internet access and freedom of speech, both of them seen and understood as fundamental and human rights. The internet, in this context, is the primary environment in the analysis of the question. It stands out the emergence of so-called "fifth-generation rights". The matter is addressed by doctrinal and normative analysis, especially in the last aspect the analysis of "Marco Civil da Internet" in Brazil, the European Union directives and the decision of French Constitutional Council about so-called Hadopi Law as well as United Nations resolutions. Finally, it affirmed the need for protection of human and fundamental rights in the digital environment and is considered the use of standards from community sources or international treaties to expand the protection of such rights.
\end{abstract}

Keywords: Law, Human Rights and Fundamental, Internet, Freedom of Expression, Right to Internet Access 


\section{SUMÁRIO}

INTRODUÇAO; 1 NOVAS TECNOLOGIAS E NOVOS DIREITOS; 1.1 Os três tempos do espírito: a linguagem oral, a escrita e a informática; 1.2 Novos direitos e o papel de empresas multinacionais; 2 NOVAS TECNOLOGIAS E OS DIREITOS HUMANOS E FUNDAMENTAIS; 2.1 Liberdade de expressão; 2.2 Direito de acesso à internet; 3 PERSPECTIVAS NORMATIVAS NA PROTEÇÃO DE DIREITOS HUMANOS E FUNDAMENTAIS NA INTERNET; 3.1 O Marco Civil da Internet; 3.2 Os direitos de acesso às novas tecnologias na União Europeia; 3.2 Resolução das Nações Unidas sobre o assunto; CONCLUSÃO; REFERÊNCIAS

\section{INTRODUÇÃO}

A ampliação do uso das novas tecnologias informacionais reflete-se em todas as áreas da ciência jurídica. ${ }^{1}$ A própria relação entre os estados e a mudança do conceito de soberania tem como uma das causas o "avanço dos meios de informação", demonstrando assim o amplo espectro de modificações causadas pelas novas tecnologias. Esta alteração na soberania é explicada, principalmente, pela ampliação do processo de globalização econômica e cultural e também pela diminuição das distâncias proporcionada pela massificação da Internet e facilitação das comunicações em geral. $^{2}$

Neste contexto, ainda, Têmis Limberger afirma que os próprios elementos referenciais do estado moderno foram afetados pelas novas tecnologias eis que "a Internet muda o clássico conceito de território, e a noção de soberania também sofre transformações." ${ }^{3}$ Há quem fale até

1 Sobre a influência da chamado Direito Virtual com os ramos do Direito ver a lição de ROHRMANN, Carlos Alberto. Curso de Direito Virtual. Belo Horizonte: Del Rey, 2005. p. 40 a 48 . Ver também LEONARDI, Marcel. Tutela e privacidade na Internet. São Paulo: Saraiva. 2012, p. 35, quando diz que seriam oito as grandes áreas do Direito da Informática: regulação dos bens de informação, proteção de dados pessoais, regulação jurídica da Internet, propriedade intelectual e informática, delitos informáticos, contratos informáticos, aspectos trabalhistas da informática e valor probatório dos suportes atuais de informação.

2 ROCHA, Patrícia Barcelos Nunes de Mattos. Direitos humanos, globalização e soberania. Revista eletrônica da Faculdade de Direito de Campos, Campos dos Goytacazes, RJ, v. 2, n. 2, abr. 2007. Disponível em: <http://www.fdc.br/Arquivos/Revista/21/01.pdf>. Acesso em: 08 jul. 2009, p. 8 e 9. Assim ensina a autora: "No começo do século XXI a sociedade internacional, por um lado definido pela interação cultural devido ao avanço dos meios de informação, pelo processo de globalização da economia as distâncias foram reduzidas, não há em como falar em soberania absoluta, já que este é um conceito desenvolvido à época da formação dos Estados Nacionais, onde tudo girava em torno da Europa."

3 LIMBERGER, Têmis. Direito e informática: o desafio de proteger os direitos do cidadão. In SARLET, Ingo Wolfgang (org). Direitos Fundamentais, Informática e Comunicação: algumas aproximações. Porto Alegre: Livraria do Advogado, 2007, p. 200. No mesmo sentido ver, NEVES, Marcelo. Transconstitucionalismo. São Paulo: Martins Fontes, 2009, p. 26, quando diz que "afirmar o vínculo a uma territorialidade delimitada como característica de uma sociedade implica desconhecer até mesmo a existência de sociedades nômades no passado, especialmente no caso de comunidades arcaicas."

REDESG / Revista Direitos Emergentes na Sociedade Global - www.ufsm.br/redesg v. 1, n. 1, jan.jun/2012 
na sociedade moderna vista como uma "sociedade mundial", estando as formações sociais desvinculada "das organizações políticas territoriais".4

O caráter universalizador e massificante da cultura como consequência da ampla utilização das novas tecnologias da informação unifica os anseios pela busca por direitos. Heiner Bielefeldt pergunta logo no início da obra Filosofia dos Direitos Humanos: "A caminho de uma ordem internacional de direitos humanos?" ${ }^{5}$ A autora destaca que nem sempre sua "aprovação generalizada" - dos direitos humanos - foi tão evidente como o é hoje. Essa "aprovação generalizada" abrange, inclusive, conforme será visto a seguir, a consideração de direitos humanos fundamentais na esfera das relações informáticas.

Ao mesmo tempo, a pós-modernidade é caracterizada pela ampliação da comunicação intercultural. Erik Jayme afirma que não se trata simplesmente da rapidez na transmissão de informações, mas também no aparecimento de uma "desejo de se comunicar" que surge como uma força irresistível. A comunicação, em uma sociedade mundial e em rede, faz parte da integração. ${ }^{6}$

Desta maneira, e observado este contexto, o trabalho abordará a influência das novas tecnologias nos direitos humanos e fundamentais. 0 foco das observações está limitado ao direito de acesso à Internet e ao direito de liberdade de expressão em tal ambiente.

\section{NOVAS TECNOLOGIAS E NOVOS DIREITOS}

Inicialmente, é necessário apontar a distinção entre os conceitos de direitos humanos e de direitos fundamentais. Em breve síntese, adota-se a lição de diferenciação formal proposta por Ruy Barbedo Antunes, que entende que os direitos fundamentais estão vinculados a um ordenamento jurídico particular enquanto que os direitos humanos possuem um caráter universal

4 NEVES, Marcelo. Ibid, p. 26: "Mas a sociedade moderna nasce como sociedade mundial, apresentandose como uma formação social que se desvincula das organizações políticas territoriais, embora estas, na forma de Estados, constituam uma das dimensões fundamentais à sua reprodução. Ela implica, em princípio, que o horizonte das comunicações ultrapassa as fronteiras territoriais do Estado."

5 BIELEFELDT, Heiner. Filosofia dos direitos humanos. São Leopoldo: Ed. Unisinos, 2005, p. 11.

6 JAYME, Erik. Identité culturelle et intégration: Le droit internationale privé postmoderne. Cours général de droit international privé. Recueil des cours de l'Académie de Droit International de la Haye. Hague, v. 251, 1996, p. 257: “Un autre trait caractéristique de la culture postmoderne est la communication interculturelle. Ce n'est pas seulement la rapidité de la transmission des informations au moyen d'instruments techniques comme le télécopieur ou la télévision qui facilite une telle communication, mais c'est aussi la volonté de communiquer qui surgit comme une force irrésistible. L'on est différent, mais l'on parle aux autres personnes. Il y a un intérêt mutuel d'un échange des idées interculturelles. Communiquer, c'est aussi s'intégrer dans une société mon- diale sans frontières."

REDESG / Revista Direitos Emergentes na Sociedade Global - www.ufsm.br/redesg v. 1, n. 1, jan.jun/2012 
e "resultam de uma formulação internacional" sendo, em função disto, mais amplos. ${ }^{7}$ Ainda, segundo o autor, os direitos humanos são fundamentais, embora nem todos o sejam. Já os direitos fundamentais estão "aprisionados nas fronteiras de um Estado". ${ }^{8}$

Os direitos humanos, como é sabido, têm uma composição histórica. Isso significa que dependendo do momento histórico, sua disposição será diferente. Isto é especialmente relevante, neste caso, uma vez que as mudanças históricas, no que se refere às novas tecnologias informáticas, certamente possuem forte impacto na compreensão - e ampliação dos direitos humanos e fundamentais. E é diante da evolução histórica dos direitos que José Alcebíades de Oliveira Júnior propõe a existência dos chamados direitos de quinta geração, ou seja, aqueles vinculados ao uso das novas tecnologias. ${ }^{9}$

Da mesma forma, Cesar Luiz Pasold traz a ideia de direitos de quinta geração. Este autor afirma que as inovações sociais e dos meios de comunicação induzem, obrigatoriamente, à análise de novas carências que implicam também em novas demandas (novos direitos) ${ }^{10}$. Tais demandas estão profundamente relacionadas com o próprio uso da Internet como mecanismo de

7 ANTUNES, Ruy Barbedo. Direitos fundamentais e direitos humanos: a questão relacional. Revista da Escola de Direito de Pelotas. v. 6 (1), Jan.-Dez./2005, p. 334: "Talvez seja este um critério de diferenciação entre direitos fundamentais e direitos humanos: os primeiros se vinculam a ordenamentos jurídicos particulares e específicos, ao passo que os segundos se revestem de universalidade e resultam de uma formulação internacional”

8 Ibid., p. 341. No mesmo sentido CANOTILHO, José Joaquim Gomes. Direito Constitucional. 6. ed. Coimbra: Almedina, 1993, p. 517: "direitos do homem são direitos válidos para todos os povos e em todos os tempos (dimensão jusnaturalista-universalista); direitos fundamentais são os direitos do homem jurídico-institucionalmente garantidos e limitados espacio-temporalmente." 0 autor explica ainda que "muitos dos direitos fundamentais são direitos da personalidade, mas nem todos os direitos fundamentais são direitos da personalidade." p. 520.

9 OLIVEIRA JÚNIOR, José Alcebíades de. Teoria Jurídica e Novos Direitos. Rio de Janeiro: Lumen Juris, 2000 , p. 86. Os direitos de quinta geração são aqueles "advindos com a chamada realidade virtual, que compreendem o grande desenvolvimento da cibernética na atualidade, implicando o rompimento de fronteiras, estabelecendo conflitos entre países com realidades distintas, via Internet." O autor amplia para cinco as três gerações inicialmente propostas por Bobbio. Também sobre as três gerações de direitos fundamentais ver: FERREIRA FILHO, Manoel Gonçalves. Direitos humanos fundamentais. 3. ed. São Paulo: Saraiva, 1999, p. 6: “Na verdade, o que aparece no final do século XVII não constitui senão a primeira geração de direitos fundamentais: as liberdades públicas. A segunda virá logo após a primeira Guerra Mundial, com o fido de complementá-la: são os direitos sociais. A terceira ainda não plenamente reconhecida, é a dos direitos de solidariedade." Este autor também faz importante ressalva ao que chama de vulgarização de direitos quando diz que "é preciso, todavia, ter consciência de que a multiplicação de direitos 'fundamentais' vulgariza e desvaloriza a ideia", p. 67.

10 PASOLD, Cesar Luiz. Novos Direitos: conceitos operacionais de cinco categorias que thes são conexas. Revista Sequência, n. 50, jul. De 2005, p. 224. No mesmo sentido ver PEREIRA, Julia Lafayette; ROTT, Rafael; SALDANHA, Jânia Maria Lopes Saldanha. A efetividade dos direitos humanos de terceira geração: a análise de um caso venezuelano. Revista Eletrônica do Curso de Direito da UFSM. vol. 2, n. 3, Novembro de 2007. Disponível em <http://www.ufsm.br/revistadireito/v2n3.html>. Acesso em: 29 de jul. 2009.

REDESG / Revista Direitos Emergentes na Sociedade Global - www.ufsm.br/redesg v. 1, n. 1, jan.jun/2012 
comunicação. Igualmente, a consideração de tais direitos adequa-se com um dos pilares dos direitos humanos que é, justamente, a emancipação. ${ }^{11}$

O aparecimento de novos direitos, neste caso os direitos de quinta geração, está relacionado também com a mudança do paradigma de uma sociedade industrial para uma sociedade informacional. Castells afirma que uma das características deste novo paradigma é a "penetrabilidade dos efeitos das novas tecnologias"12. Se a informação é necessária para as atividades humanas "todos os processos de nossa existência individual e coletiva são diretamente moldados (embora, com certeza, não determinados) pelo novo meio tecnológico." ${ }^{13}$ Diante disto é que se faz necessário o entendimento da ideia de inclusão digital, neste trabalho, visto por meio dos direitos de acesso e de liberdade de expressão, ambos na Internet.

José Alcebíades de Oliveira Júnior, ao tecer comentários sobre o multiculturalismo, afirma também que "não há como negar que as relações sociais e institucionais estão atravessadas por valores culturais diferenciadores que se traduzem em um jogo de poder e dominação". Este jogo de poder e dominação, na sociedade atual, também é influenciado pelas novas tecnologias. ${ }^{14}$ Inclusive, é possível citar as recentes manifestações políticas na região do Norte da África, nas quais a Internet teve um papel fundamental na mobilização da população em suas reivindicações por justiça, sendo possível afirmar que a Internet possui um grande "potencial democratizante". ${ }^{15}$

11 SANTOS, Boaventura de Sousa. Os direitos humanos na pós-modernidade. Oficina do CES - Centro de Estudos Sociais, Coimbra, n. 10, Junho de 1989, p. 3. Segundo o autor, este pilar é "constituído por três lógicas ou tipos de racionalidade: a racionalidade estético-expressiva da arte e da literatura, a racionalidade moral-prática da ética e do direito e a racionalidade cognitiva-instrumental da ciência e da técnica."

12 CASTELLS, Manuel. A sociedade em rede. 6. ed. São Paulo: Paz e Terra, 1999, p. 108.

13 Ibid., p. 108.

14 OLIVEIRA JÚNIOR, José Alcebíades de. Cultura democrática para direitos humanos multiculturais. In Revista Estudos Jurídicos. V. 40 (2). jul. - dez. 2007. São Leopoldo. Unisinos. Disponível em <http://www.unisinos.br/publicacoes_cientificas/images/stories/Publicacoes/estudos_juridicosvol40n2/7 9a83_art05_oliveira_junior\%5Brev_ok\%5D.pdf>. Acesso em: 14 jun. 2009, p. 80. Isso pode ser afirmado, principalmente, pelo poder de organização que as redes sociais permitem. Muitos grupos políticos e de ativismo reúnem-se por meio de redes sociais. Já Manuel Castells afirma que a internet "é a base da comunicação em nossas vidas, para trabalho, conexões pessoais, informações, entretenimento, serviços públicos e religião." CASTELLS, Manuel. Ibid., p. XI. Nota-se aqui a importância que o autor dá para a Internet, uma vez que ela abrange todas as dimensões do humano (ética, política, artística, econômica, religiosa e científica).

15 UNITED NATIONS. Report of the Special Rapporteur on the promotion and protection of the right to freedom of opinion and expression - A/HRC/17/27. Report . Disponível em: <http://www.unhcr.org/refworld/docid/49f8416d2.htm>. Acesso em: 10 jun. 2012, p. 4. Quanto à questão do "potencial democratizante" ver LEONARDI, Marcel. Internet e regulação: o bom exemplo do Marco Civil da Internet. Revista do Advogado, São Paulo, n. 115, ano XXXII, abr. 2012, p. 109: “As recentes REDESG / Revista Direitos Emergentes na Sociedade Global - www.ufsm.br/redesg v. 1, n. 1, jan.jun/2012 
Para a melhor compreensão do alcance das novas tecnologias na ampliação do conhecimento humano e sua relação com as liberdades de comunicação é trazida a lição de Pierre Levy, que será abordada a seguir.

\subsection{Os três tempos do espírito: a linguagem oral, a escrita e a informática.}

O filósofo francês Pierre Lévy explica a evolução da humanidade por meio do aspecto da linguagem como tecnologia intelectual. Ao adentrar no campo da psicologia cognitiva, o autor traz a simbologia dos três tempos do espírito: a oralidade, a escrita e a linguagem informática ${ }^{16}$. Em suas palavras "linguagem e técnica contribuem para produzir e modular o tempo"17.

A evolução do conhecimento e, consequentemente, da sociedade apoiam-se na evolução da forma com que o conhecimento é transmitido. A oralidade primária tinha na palavra falada o papel hoje comparado ao da escrita no que diz respeito à transmissão de conhecimento. Nesta, a "palavra tem a função básica de gestão da memória social”"18. Em uma sociedade oral, a lembrança representa o papel mais importante já que a memória pessoal (baseada apenas na mente humana, e em nenhum outro instrumento tecnológico) é o vetor de transmissão do conhecimento. Neste método a importância recai na associação mental de ideias e na criação de causas e efeitos que criam as conexões de lembranças.

No entanto, o método de transmissão oral do conhecimento não foi suficiente para abarcar o anseio de evolução da humanidade. Com o aparecimento da escrita, nasce também a teoria, a lógica e as sutilezas de interpretação. Com a escrita, há também o alfabeto, a impressão do conhecimento e a ciência. ${ }^{19}$ Igualmente, nascem as leis escritas, os dogmas religiosos, o embrião do estado e as primeiras civilizações históricas. ${ }^{20} \mathrm{~A}$ escrita, inventada no florescer das civilizações agrícolas, redefiniu também a compreensão do tempo: ela eterniza o conhecimento! Se antes - na tradição oral - era necessário o intermediário humano presente no ato de transmitir o conhecimento, com a escrita este intermediário é eliminado. Sem o

reformas políticas e a queda de regimes totalitários em diversos países do mundo, parcialmente facilitadas pelo uso de ferramentas on-line, evidenciam o potencial democratizante da Internet."

16 LÉVY, Pierre. As tecnologias da inteligência. Rio de Janeiro: Editora 34, 1993, p. 76.

17 Ibid., p. 76.

18 Ibid., p. 76.

19 Ibid., p. 87.

$20 \quad$ Ibid., p. 88.

REDESG / Revista Direitos Emergentes na Sociedade Global - www.ufsm.br/redesg v. 1, n. 1, jan.jun/2012 
intermediário, portanto, a transmissão do conhecimento é mais rápida e atinge, ao mesmo tempo, mais pessoas.

Se as conexões entre as ideias, na oralidade e na escrita, são limitadas pela memória humana ou pelos limites estáticos do papel, na informática apoiam-se na grandeza e dinamicidade da memória computacional.

A informática permite e proporciona uma evolução cognitiva que amplia o acesso do homem ao conhecimento. Com a massificação das novas tecnologias todos são emissores e receptores de informação ao mesmo tempo. Esta circunstância reforma e redesenha o espectro da liberdade de expressão e comunicação. ${ }^{21} \mathrm{~A}$ ampliação das conexões entre as informações e as pessoas também é uma consequência do uso das tecnologias da informação. Porém, estas conexões, muitas vezes, são proporcionadas por grandes empresas multinacionais responsáveis por serviços e produtos prestados na sociedade digital, o que será tratado a seguir.

\subsection{Novos direitos e o papel de empresas multinacionais}

A natureza e as interações do saber com a liberdade de comunicação e expressão , na era pós-moderna, são definidas e até mesmo condicionadas pela liberdade de expressão nos meios tecnológicos. Já em 1979, Jean-François Lyotard comentava sobre "o saber nas sociedades informatizadas" em sua obra "O pós-moderno", prevendo que este saber terá de ser obrigatoriamente traduzido para "linguagem de máquina" sob pena de ser abandonado. ${ }^{22}$

A questão de como as empresas multinacionais interagem com os conteúdos na internet também já tinha sido intuída por Lyotard nos anos $70^{23}$. Atualmente, discute-se como grandes

\footnotetext{
21 De acordo com BAUMAN, Zygmunt. Tempos Líquidos. Rio de Janeiro: Jorge Zahar, 2007, p. 11: “Em primeiro lugar, num planeta atravessado por 'auto-estradas da informação', nada que acontece em alguma parte dele pode de fato, ou ao menos potencialmente, permanecer do 'lado de direitos humanosfora' do intelectual. Não há terra nulla, não há espaço em branco no mapa mental, não há terra nem povo desconhecidos, muito menos incognoscíveis."

22 LYOTARD, Jean-François. O pós-moderno. Rio de Janeiro: José Olympio, 1986, p. 4: “Nesta transformação geral, a natureza do saber não permanece intacta. Ele não pode se submeter aos novos canais, e tornar-se operacional, a não ser que o conhecimento possa ser traduzido em quantidades de informação. Pode-se então prever que tudo o que no saber constituído não é traduzível será abandonado, e que a orientação das novas pesquisas se subordinará à condição de tradutibilidade dos resultados eventuais em linguagem de máquina."

${ }_{23}$ Ibid., p. 6: "Estas formas [as multinacionais] implicam que as decisões relativas ao investimento escapam, pelos menos em parte, ao controle dos Estados-nações. Com a tecnologia informacional e telemática, a questão corre o risco de tornar-se ainda mais espinhosa. Admitamos, por exemplo, que uma REDESG / Revista Direitos Emergentes na Sociedade Global - www.ufsm.br/redesg v. 1, n. 1, jan.jun/2012
} 
multinacionais da Tecnologia da Informação e Comunicação, como o Google por exemplo, influenciam na liberdade de expressão e como apoiam, em certos casos, países de regimes totalitários. Como estas empresas possuem mecanismos de controle de informação elas podem, de acordo com suas próprias regras de uso ou ainda por meio de ordens judiciais, retirar qualquer conteúdo que estiverem sob seu domínio.

No artigo Corporate Complicity in Internet Censorship in China: Who Cares for the Global Compact or the Global Online Freedom Act?, a mesma preocupação é abordada quando se faz referência à questão da responsabilidade que empresas multinacionais têm na violação de direitos humanos, especialmente nos casos de censura da internet na China. As grandes corporações internacionais apoiariam, por meio da implementação de tecnologias específicas, o bloqueio de conteúdo. ${ }^{24}$

O papel das grandes empresas multinacionais é fundamental para a compreensão de um cenário de globalização, onde está inserida a discussão acerca da proteção de direitos humanos e fundamentais relacionados com as novas tecnologias. A “intensificação vertiginosa da transnacionalização da produção de bens e serviços e dos mercados financeiros”25, como ensina Boaventura de Sousa Santos, é sustentada também pelas empresas multinacionais que "passaram a ter uma preeminência sem precedentes como atores internacionais" ${ }^{26}$. Com isso, em função do controle que tais empresas exercem nas tecnologias de informação e comunicação, elas passam a ser também atores envolvidos na problemática de proteção - e violação - dos direitos fundamentais e humanos. Seu papel pode estar tanto na ampliação e instrumentalização de direitos como também no seu impedimento ou limitação, uma vez que em função da

firma como a IBM seja autorizada a ocupar uma faixa do campo orbital da Terra para implantar satélites de comunicação e/ou de banco de dados. Quem terá acesso a isto? Quem definirá os canais ou os dados proibidos? 0 estado?"

24 DEVA, Surya. Corporate Complicity in Internet Censorship in China: Who Cares for the Global Compact or the Global Online Freedom Act?. George Washington International Law Review, Vol. 39, p. 255-319, 2007. Disponível em <SSRN: http://ssrn.com/abstract=964478>. Acesso em: 14 maio 2009, p. 264. Mais adiante, p. 317, a autora destaca que: "The involvement of Yahoo!, Microsoft, Google, and Cisco in Internet censorship in China illustrates how a "public-private cartel" for Internet censorship can not only curtail the right to information or the freedom of speech and expression, but also abridge other important human rights."

25 SANTOS, Boaventura de Sousa. Para uma Concepção Multicultural dos Direitos Humanos. Contexto Internacional, Rio de Janeiro, vol. 23, $\mathrm{n}^{\circ}$ 1, jan/jun 2001, p. 10.

26 Ibid., p. 10-11. Acerca do conceito de globalização, o autor tem a seguinte definição: "é o processo pelo qual determinada condição ou entidade local estende a sua influência a todo o globo e, ao fazê-lo, desenvolve a capacidade de designar como local outra condição social ou entidade rival." Desta maneira, "não existe condição global para a qual não consigamos encontrar uma raiz local, uma imersão cultural específica".

REDESG / Revista Direitos Emergentes na Sociedade Global - www.ufsm.br/redesg v. 1, n. 1, jan.jun/2012 
transnacionalidade, os Estados podem não ter meios jurídicos para alcançar os atos de tais empresas. É neste contexto que são verificados os novos direitos e as soluções para seu pleno exercício.

\section{NOVAS TECNOLOGIAS E OS DIREITOS HUMANOS E FUNDAMENTAIS}

A inclusão de novos direitos no rol dos direitos fundamental é possível, no ordenamento brasileiro, por meio da análise do parágrafo segundo do art. $5^{\circ}$ da CF. Ele estabelece uma abertura à abrangência de novos direitos fundamentais "decorrentes do regime e dos princípios por ela [a Constituição] adotados”.

Canotilho ensina que esta abertura dá vazão aos chamados "direitos materialmente fundamentais" em oposição aos "direitos fundamentais formalmente constitucionais", estes sim enunciados em normas constitucionais. ${ }^{27}$

Desta forma, a Constituição Federal faz uma “enumeração exemplificativa” por meio dos direitos formalmente estabelecidos. Nada impede que outros direitos sejam deduzidos através de uma análise sistêmica dos próprios dispositivos da Constituição para a composição de novos direitos. O caráter exemplificativo dos direitos fundamentais é reforçado ainda pelo próprio fato da Constituição admitir a possibilidade de reconhecimento de direitos provenientes de tratados internacionais. ${ }^{28}$

Com isso, passa-se à análise de tais direitos no contexto estabelecido para este trabalho.

\subsection{Liberdade de expressão}

27 CANOTILHO, José Joaquim Gomes. Ibid., p. 528. No mesmo sentido ALEXY, Robert. Teoria de los derechos fundamentales. Trad. VALDÉS, Ernesto Garzón. Madrid: Centro de Estudios Constitucionales, 1993, p. 70-71: "las normas de derecho fundamental directamente estatuidas por la Constitución y las normas de derecho fundamental a ellas adscriptas. [...] Una norma adscripta vale y es una norma de derecho fundamental si para su adscripción a una norma de derecho fundamental estatuida directamente es posible dar una fundamentación iusfundamental correcta."

28 FERREIRA FILHO, Manoel Gonçalves. Ibid., p. 98.

REDESG / Revista Direitos Emergentes na Sociedade Global - www.ufsm.br/redesg v. 1, n. 1, jan.jun/2012 
Se o mundo virtual é uma reprodução do "mundo real", se a Internet passa a ser vista e utilizada como um meio para a propagação de conteúdos e de discursos, é necessária a proteção dos direitos fundamentais e humanos em seu ambiente. ${ }^{29}$ Com a massificação do uso das novas tecnologias, o bloqueio indevido e o controle exagerado ou ilegal de informações afetam diretamente a liberdade de expressão. ${ }^{30}$

Ao mesmo tempo em que a tecnologia amplia o rol de direitos a serem protegidos, a sua privação enseja, por sua vez, a supressão de direitos. Se o direito a educação formal é um requisito para o acesso ao conhecimento e à cultura, o acesso às novas tecnologias passa a ser um requisito de igual importância. ${ }^{31}$

Jack Balkin sustenta que as novas tecnologias modificam as condições sociais nas quais as pessoas desenvolvem o seu discurso. ${ }^{32} \mathrm{~A}$ revolução digital, nas palavras do autor, permite a ampliação da participação cultural de forma mais abrangente do que as tecnologias de rádio e televisão proporcionaram no passado. Mas, ao mesmo tempo, há a possibilidade de limitação e controle desta participação pelas próprias tecnologias. ${ }^{33} 0$ autor ressalta ainda que uma cultura democrática é aquela que dá a todos (independente de participar de uma elite econômica, política ou cultural) a chance de participar de sua produção. ${ }^{34}$ Neste ponto é que se entende a valorização do acesso às novas tecnologias como requisito fundamental para o incremento dessa participação cultural democrática. A desvinculação do discurso com uma elite econômica, por exemplo, é viável pois os custos de comunicação caem consideravelmente com as novas tecnologias. Logo, com a diminuição dos custos, a liberdade de expressão também é ampliada. ${ }^{35}$

\footnotetext{
29 Atualmente quase todos (senão todos) os meios de comunicação tradicionais como televisão, jornais e rádio, também utilizam a Internet para a publicação de conteúdos. A atividade dos leitores-espectadores fica mais relevante na medida que eles também conseguem publicar informações no ambiente digital, com a mesma facilidade que os veículos de comunicação tradicionais.

${ }_{30}$ Neste sentido, observar MICHELMAN, Frank I... Relações entre democracia e liberdade de expressão: discussão de alguns argumentos . In SARLET, Ingo. Wolfgang (org). Direitos Fundamentais, Informática e Comunicação: algumas aproximações. Porto Alegre: Livraria do Advogado, 2007, p. 51. 0 autor fala sobre a concepção material de liberdade de expressão que significaria que "as oportunidades e capacidades comunicativas de alguns membros da sociedade não estão sendo injustamente oprimidas por atos e decisões, não só do Estado, mas de outros agentes da sociedade".

31 Cf. PASOLD, Cesar Luiz, Ibid., p. 232, surgem, com os Novos Direitos, novos bens da vida que passam a ser juridicamente tutelados, bens estes com difícil valoração econômica.

32 BALKIN, Jack M.. Digital Speech and Democratic Culture: a Theory of Freedom of Expression for the Information Society. New York University Law Review, Vol. 79, No. 1, 2004. N. 63. Disponível em: <http://ssrn.com/abstract=470842 or DOI: 10.2139/ssrn.470842>. Acesso em: 05 jun. 2009, p. 2.

33 Ibid., p. 2.

34 Ibid., p. 3.

35 Ibid., p. 8.

REDESG / Revista Direitos Emergentes na Sociedade Global - www.ufsm.br/redesg v. 1, n. 1, jan.jun/2012
} 
Outro aspecto importante acerca da liberdade de expressão na Internet é o de que, antes da revolução informacional, a ampla liberdade de manifestação e publicação de conteúdos baseava-se na propriedade dos meios de comunicação (redes de TV, satélites de comunicação, jornais, etc). A vinculação do discurso com a propriedade dos meios de comunicação condiciona sua natureza política e ideológica. Com a viabilização da ampla comunicação igualitária e de baixo custo, há a ampliação da liberdade de expressão. ${ }^{36}$ Tanto que em países onde não há meios de comunicação independentes, a Internet, por meio das plataformas colaborativas e das redes sociais, contribui para a ampla divulgação de fatos e também para o progresso como um todo. ${ }^{37}$ É possível afirmar que a liberdade de expressão permite e habilita o exercício de outros direitos humanos. ${ }^{38}$ Trata-se não apenas de um direito individual mas um direito de composição coletiva, com reflexos sociais importantes para a coletividade.

Questão que também merece destaque é a relacionada com a regulação do conteúdo nos meios digitais, que pode ocorrer de diversas formas. É certo que, em primeira análise, o controle antecipado de conteúdo, leia-se censura prévia, é vedado pela Constituição Federal em seu art. $5^{\circ}$, inc. IX. Esta circunstância, inclusive, é a que enseja o fato dos provedores não possuírem um dever ativo de monitorar o conteúdo de seus usuários. ${ }^{39}$

Porém, há sempre a possibilidade de um controle legítimo e a posteriori da informação, em função, por exemplo, da publicação de discursos com conteúdo ofensivo ou criminoso. ${ }^{40}$ Com isso, o livre discurso é a regra e não a exceção.

O problema ganha novos contornos, por sua vez, se for considerada a chamada Web 2.0 onde os usuários produzem conteúdos por meios de blogs, redes sociais, sites de vídeo, etc. Tal circunstância ainda é agravada pela falta de uma harmonização internacional acerca do tratamento da questão. Se a Internet é transnacional, se as empresas de prestação de serviços

\footnotetext{
36 Ibid., p. 19.

37 UNITED NATIONS. Report of the Special Rapporteur on the promotion and protection of the right to freedom of opinion and expression - A/HRC/17/27. Report . Disponível em: <http://www.unhcr.org/refworld/docid/49f8416d2.htm>. Acesso em: 10 jun. 2012, p. 7.

38 Ibid. p. 7. No mesmo sentido, CHANDER, Anupam. Whose Republic? University of Chicago Law Review, vol. 69, n. 3, 2002. Disponível em: <http://ssrn.com/abstract=417600>. Acesso em: 12 jan. 2012, p. 1481, diz: "Cyberspace helps give members of minority groups a fuller sense of citizenship-a right to a practice of citizenship that better reflects who they are. It does so by helping to counter the assimilationist tendencies of mass culture, mass politics, and economics. In this way, cyberspace plays an important role in the multicultural project of including everyone in political and civic society. "

39 É o que prevê o Marco Civil da Internet, em seu art. $9^{\circ}$, \$3, que diz: "Na provisão de conexão à Internet, onerosa ou gratuita, é vedado bloquear, monitorar, filtrar, analisar ou fiscalizar o conteúdo dos pacotes de dados, ressalvadas as hipóteses admitidas na legislação.

40 No último caso, tem-se como exemplo a questão de conteúdos envolvendo pornografia infantil e racismo.
}

REDESG / Revista Direitos Emergentes na Sociedade Global - www.ufsm.br/redesg v. 1, n. 1, jan.jun/2012 
neste meio também o são, a incongruência das leis internas sobre a matéria pode fazer com que alguém em um país seja afetado pelas disposições legais de outro. Além do mais, as diferenças culturais entre os países também influenciam a questão do bloqueio de conteúdos na Internet.

A questão também abrange o problema de bloqueios muito amplos. Sob certas condições e dependendo do meio técnico utilizado para a realização do bloqueio, há o risco de bloquear outros conteúdos além daquele considerado ilícito. No Brasil, cita-se o exemplo do caso Daniella Cicarelli que, em função de uma ordem judicial mal cumprida, promoveu o bloqueio de todo o site Youtube no Brasil. Note-se que em função do vídeo objeto da demanda bloqueou-se outros milhões de vídeos que não eram considerados ilícitos. ${ }^{41}$

Outras situações em que o bloqueio ampliado pode ocorrer é quando um servidor de Internet hospeda diversos sites, situação esta considerada bastante comum e corriqueira. Caso este servidor possua um único endereço IP, se este for bloqueado, todos os outros sites que estiverem hospedados neste servidor também o serão. ${ }^{42}$

Com isso, o bloqueio de conteúdos sem a violação explícita de uma norma criminal, sem uma decisão judicial específica ou ainda realizado de maneira muita ampla, bloqueando também conteúdos legítimos, via de regra, viola a liberdade de expressão na Internet. ${ }^{43}$

\subsection{Direito de acesso à Internet}

Em um estudo promovido pela Consultoria Legislativa da Câmara dos Deputados intitulado “Legislação sobre Internet no Brasil" é realizada uma análise acerca da democratização do acesso à Internet. Neste estudo é mencionado o Plano de Inclusão Digital do Governo Federal, assim previsto no Plano Plurianual 2004-2007. Entre os

41 Sobre o caso Cicarelli ver DA SILVA, Regina Beatriz Tavares. Sistema protetivo dos direitos da personalidade. In DA SILVA, Regina Beatriz Tavares; DOS SANTOS, Manoel J. Pereira (coord.). Responsabilidade Civil na Internet e nos demais Meios de Comunicação. São Paulo: Saraiva, 2007, capítulo I.

42 Para uma explicação completa da questão referente ao bloqueio de conteúdos por meio de endereço IP ver LEONARDI, Marcel. Tutela e privacidade na Internet. São Paulo: Saraiva, 2012, p. 297-305.

43 Neste sentido ver AKDENIZ, Yaman. To block or not to block: European approaches to content regulation, and implications for freedom of expression. Computer Law \& Security Review, v. 26, n. 3, p. 260-272, 2010. Elsevier Ltd. Disponível em: <http://linkinghub.elsevier.com/retrieve/pii/ S0267364910000518>. Acesso em: 17 Jul. 2012, p. 5: "On the one hand, the requirement for 'a legal basis' for blocking is a desired and welcome move from a European Convention on Human Rights point of view. On the other hand, this highlights the fact that currently many hotlines within the European Union region function and order blocking access to content and websites without a legal basis triggering legitimate accusations of vigilantism."

REDESG / Revista Direitos Emergentes na Sociedade Global - www.ufsm.br/redesg v. 1, n. 1, jan.jun/2012 
objetivos propostos há a ampliação da proporção de cidadãos com acesso às Tecnologias da Informação e Comunicação e também a ampliação de centros de acessos comunitários à internet. ${ }^{44}$

Ademais, também é citado o programa de massificação da banda larga, que inclui a ampliação deste acesso nas escolas e telecentros, além de programas de recondicionamento de computadores usados. ${ }^{45}$ Igualmente, o governo Brasileiro, por meio do chamado Programa Nacional de Banda Larga (PNBL), assim instituído pelo Decreto 7.175/2010 e mantido pelo Comitê Gestor do Programa de Inclusão Digital (CGPID), tem o objetivo principal de "fomentar e difundir o uso e o fornecimento de bens e serviços de tecnologias de informação e comunicação". ${ }^{46}$ Com isso, é possível verificar a preocupação do Estado brasileiro em ampliar a inclusão digital por meio do referido plano. No entanto, a mera preocupação do Estado em promover e ampliar o acesso à Internet para todas as camadas não é suficiente, por si só, para a definição e o reconhecimento do direito fundamental de acesso à Internet.

Ivan Hartmann sustenta a ideia de que há um direito fundamental de acesso à internet. Ele faz isso partindo do pressuposto de que o rol dos direitos fundamentais trazido na Constituição Federal não é fechado - como afirmado anteriormente-, abrangendo assim novos direitos baseados na interpretação da norma bem como na dinamicidade da sociedade. ${ }^{47}$

Ao efetuar uma classificação do direito de acesso à Internet o autor propõe tratar-se de um direito de defesa (quanto à proteção dos dados) e um direito contra o Estado e particulares (pois deve respeitar a liberdade de expressão). ${ }^{48}$ Pode ser

\footnotetext{
44 VELOSO, Elisabeth Machado. Legislação sobre internet no Brasil. Brasilia: Câmara dos Deputados, 2009. Disponível em: <www.fndc.org.br/arquivos/Regulacao_internet.pdf>. Acesso em: 29 jul. 2009, p. 25.

45 Ibid., p. 26 e 27. A importância da utilização da banda larga ocorre no sentido de ampliar o acesso a novos tipos de conteúdos tais como sites com novas tecnologias, conteúdos de áudio e vídeo, etc. Acesso lentos de internet podem impedir o acesso a estes conteúdos especializados.

46 Além do disposto no Decreto 7.175/2010, mais informações podem ser encontradas no site oficial "Brasil Conectado", no endereço http://www4.planalto.gov.br/brasilconectado/CGPID.

47 HARTMANN, Ivan Alberto Martins. 0 acesso à internet como direito fundamental. 2007. $94 \mathrm{f}$. Orientador SARLET, Ingo Wolfgang. Monografia (Bacharelado em Ciências Jurídicas e Sociais). Pontifícia Universidade Católica do Rio Grande do Sul, Porto Alegre, 2007, p. 73.

48 Ibid., p. 81.

REDESG / Revista Direitos Emergentes na Sociedade Global - www.ufsm.br/redesg v. 1, n. 1, jan.jun/2012
} 
entendido ainda com um direito subjetivo de acesso (inclusive por meio da exigência de terminais públicos de acesso em bibliotecas ou centros públicos). Tem também uma dimensão negativa, visto que nem o Estado e nem terceiros podem limitar o direito de acesso por meio do bloqueio de conteúdo (e aqui há a clara ligação com a proibição da censura prévia, do art. $5^{\circ}$ inc. IX da Constituição Federal).

Já a dimensão positiva, requer "prestações jurídicas que regulem e informem o direito de acesso à Internet, permitindo que alcance a devida eficácia e efetividade”. ${ }^{49}$ A eficácia do direito passaria, segundo o autor, por ações tais como políticas públicas de inclusão digital ${ }^{50}$, como as citadas anteriormente.

Este estudo ressalta ainda a consideração do acesso à internet como direito fundamental em face do desenvolvimento da tecnologia da informação e o seu uso crescente pela sociedade. ${ }^{51}$ Um exemplo recente deste desenvolvimento está relacionado com a chamada Lei de Acesso à Informação ${ }^{52}$. Esta lei estabelece, entre outras questões relativas à transparência de dados públicos, que os órgãos públicos utilizarão a Internet tanto para a publicação de dados como recolhimento de solicitações de informações. É possível perceber, diante disto, que o próprio inc. XXXIII do art. $5^{\circ}$ da $\mathrm{CF}^{53}$ consegue ser melhor exercido com o uso da Internet o que justifica, entre outros tantos motivos, o acesso à Internet como direito fundamental. Como todos os órgãos disponibilizam informações e recolhem solicitações por meio da Internet, quem não possui acesso à Internet não possui também acesso a tais informações.

É cediço que muitos serviços privados - como bancos, companhias aéreas e todo o comércio eletrônico em geral - utilizam a Internet para a prestação de suas atividades. O contexto de ampliação do comércio eletrônico faz com que, em alguns casos, produtos

$\begin{array}{ll}49 & \text { Ibid., p. } 83 . \\ 50 & \text { lbid., p. } 85 .\end{array}$

51 A Constituição Portuguesa, por exemplo, em seu art. 35 inc. 6º refere: “A todos é garantido livre acesso às redes informáticas de uso público, definindo a lei o regime aplicável aos fluxos de dados transfronteiras e as formas adequadas de protecção de dados pessoais e de outros cuja salvaguarda se justifique por razões de interesse nacional. "

52 Lei 12.527 de 18 de Novembro de 2011.

53 Art. $5^{\circ}$, inc. XXXIII da CF: todos têm direito a receber dos órgãos públicos informações de seu interesse particular, ou de interesse coletivo ou geral, que serão prestadas no prazo da lei, sob pena de responsabilidade, ressalvadas aquelas cujo sigilo seja imprescindível à segurança da sociedade e do Estado.

REDESG / Revista Direitos Emergentes na Sociedade Global - www.ufsm.br/redesg v. 1, n. 1, jan.jun/2012 
e serviços só sejam consumidos por quem tem acesso à Internet. Desta maneira, e de acordo com o exposto até aqui, nota-se a importância do direito de acesso à Internet até para as atividades mais básicas de consumo.

\section{PERSPECTIVAS NORMATIVAS NA PROTEÇÃO DE DIREITOS HUMANOS E FUNDAMENTAIS NA INTERNET}

\section{1 - O Marco Civil da Internet}

Há no Brasil, atualmente, um grande debate acerca do projeto de lei conhecido como Marco Civil da Internet ${ }^{54}$. Como este projeto lida justamente com os direitos relacionados ao uso da Internet, um dos espaços desta discussão foi um site na Internet ${ }^{55}$ onde qualquer pessoa poderia contribuir com sugestões para seu aprimoramento. Posteriormente, foram realizadas audiências públicas por todo o país onde o projeto foi discutido com autoridades da área, ativistas e com a sociedade em geral. ${ }^{56}$

O Marco Civil da Internet recebe menção neste trabalho em função do destaque, em sua redação, dos princípios, garantias e direitos estabelecidos para o uso da Internet no Brasil. Seu art. $2^{\circ}$, inc. II, reconhece como um dos fundamentos do uso da Internet "os direitos humanos, o desenvolvimento da personalidade e o exercício da cidadania em meios digitais”. Já no art. 4, onde são dispostos os objetivos da disciplina de uso da Internet, o inc. I e II assim preveem a promoção do direito de acesso à internet para todos e também a promoção do próprio acesso à informação e ao conhecimento. 0 art. $6^{\circ}$ reforça o fato do acesso a internet ser visto como um direito humano. ${ }^{57}$ enquanto que o art. $7^{\circ}$ estabelece que "o acesso à Internet é essencial ao exercício da cidadania” e garante ao cidadão o direito de não suspensão da conexão (leia-se acesso) à Internet "salvo por débito diretamente decorrente de sua utilização".

\footnotetext{
54 Formalmente trata-se do Projeto de Lei 2126/11.

55 A descrição do projeto bem como das discussões e as audiências públicas realizadas podem ser analisadas no site http: / / culturadigital.br/marcocivil/.

56 No site http://edemocracia.camara.gov.br/web/marco-civil-da-internet/inicio pode ser verificado o substitutivo juntamente com o parecer de relatoria do Deputado Alessandro Molon.

57 Assim dispõe o art. 60: “Na interpretação desta Lei, serão levados em conta, além dos fundamentos, princípios e objetivos previstos, a natureza da Internet, seus usos e costumes particulares e sua importância para a promoção do desenvolvimento humano, econômico, social e cultural. "
}

REDESG / Revista Direitos Emergentes na Sociedade Global - www.ufsm.br/redesg v. 1, n. 1, jan.jun/2012 
Nota-se aí, na análise do chamado Marco Civil, que houve uma preocupação clara na consideração da proteção do acesso à internet como direito fundamental. Mesmo que tal direito não receba uma proteção constitucional, o Marco Civil faz uma relação direta, no art. $2^{\circ}$, inc. II, dos direitos humanos como fundamentos do uso da Internet.

Percebe-se que o Marco Civil preenche não apenas a lacuna legal referente aos direitos civis na Internet, mas também afirma e reconhece uma sociedade digital. Ele nasce em um contexto nacional de poucas legislações abordando o Direito da Tecnologia da Informação. A evolução da tecnologia sempre motivou a atualização das legislações. Foi assim com o nascimento do Direito do Trabalho e das Telecomunicações, por exemplo, e deve ser, como já pode ser percebido, também com as legislações atinentes aos novos direitos. ${ }^{58}$

As disposições do Marco Civil contribuem também para a diminuição da possibilidade de ocorrência de abusos e violações à liberdade de expressão e à própria segurança da Internet, na visão de Marcel Leonardi. Ademais, a efetividade de tutela de direitos na Internet - incluindo a liberdade de expressão - “depende, necessariamente, da capacidade de regulação pelo sistema jurídico." 59

Diante disto, o Marco Civil da Internet aparece como uma resposta da própria sociedade brasileira que anseia pela proteção e tutela de direitos relacionados com as novas tecnologias da informação. Além do mais, é por meio do Marco Civil que a promoção do direito de acesso à Internet é formalmente reconhecida no ordenamento jurídico brasileiro. Tal circunstância, por si só, justifica sua aprovação e também sua importância.

\subsection{Os direitos de acesso às novas tecnologias na União Europeia}

É possível notar a crescente preocupação dos participantes da União Europeia na implementação de normas comunitárias ressaltando a observância dos direitos humanos em relação às novas tecnologias. Especificamente em relação à liberdade de expressão, cita-se o

58 A propósito, as relações de trabalho já começam a ser rediscutidas diante das novas práticas de trabalho à distância - ou teletrabalho - que só podem ser realizadas por meio da tecnologia da informação e da Internet.

59 LEONARDI, Marcel. Internet e regulação: o bom exemplo do Marco Civil da Internet. Revista do Advogado, São Paulo, n. 115, ano XXXII, abr. 2012, p. 100.

REDESG / Revista Direitos Emergentes na Sociedade Global - www.ufsm.br/redesg v. 1, n. 1, jan.jun/2012 
item 9 da Diretiva 2000/31 da Comunidade Europeia, que relaciona este direito com a própria convenção para a proteção dos Direitos do Homem. ${ }^{60}$

No mesmo sentido, em maio de 2009, o Conselho de Ministros da Europa publicou uma declaração na qual foi reconhecido o acesso à Internet como Direito Fundamental. A referida declaração ${ }^{61}$ representou um passo importante no reconhecimento de direitos pois reconhece o direito de acesso à internet como básico para o exercício da cidadania.

Já o Conselho Constitucional Francês, em decisão de 19 de Maio 200962, julgou inconstitucional o projeto de lei que tencionava bloquear o acesso à Internet sem a necessidade de decisão judicial de pessoas que fizessem downloads de material protegido por direitos autorais. 0 projeto de lei em questão (chamada de 3 Strike Law ou lei Hadopi) previa a inserção no Código de Propriedade Intelectual Francês de um órgão administrativo chamado "High Authority for the diffusion of works and protection of copyrigh on the Internet"63. Este órgão teria o poder de aplicar sanções administrativas contra quem fizesse downloads de material protegido por direitos autorais, constando entre as penalidades a possibilidade de suspensão do acesso à internet por um período de dois meses a um $2 \mathrm{ano}^{64}$, sem a necessidade de sentença judicial. A corte entendeu que o projeto era inconstitucional por haver uma clara violação do direito fundamental à liberdade de expressão e comunicação com essa "penalidade". Igualmente, havia a violação ao direito fundamental do devido processo legal com uma punição desta natureza sem uma decisão judicial. Foi citado, inclusive, o artigo 11 da Declaração dos

60 UNIÃO EUROPEIA. Diretiva 2000/31/CE, de 8 de Junho de 2000. Jornal Oficial das Comunidades Europeias. Parlamento e Conselho Europeu. Disponível em: <http://eurlex.europa.eu/LexUriServ/LexUriServ.do?uri=OJ:L:2000:178:0001:0016:PT:PDF>. Acesso em: 10 jul. 2009. Cf. o texto do item citado é: "A livre circulação dos serviços da sociedade da informação pode em muitos casos constituir um reflexo específico, no direito comunitário, de um princípio mais geral, designadamente o da liberdade da expressão, consagrado no n. 1 do artigo $10^{\circ}$ da Convenção para proteção dos Direitos do Homem e das liberdades fundamentais, ratificada por todos os EstadosMembros."

61 1ST COUNCIL OF EUROPE CONFERECE OF MINISTERS RESPONSIBLE FOR MEDIA AND NEW COMUNICATION SERVICES. Political declaration and resolutions. 28 e 29 may 2009 . Disponível em: <http://www.ministerialconference.is/media/images/MCM2009011_en_final_web.pdf>. Acesso em: 12 jul. 2009.

${ }_{62}$ FRANCÊS, Conselho Constitucional. Partes: M. Jean-Marc AYRAULT et al., Decisão $n^{\circ}$ 2009-580 de 10 de Junho de 2009. Disponível em <http://www.conseil-constitutionnel.fr/conseilconstitutionnel/francais/les-decisions/2009/decisions-par-date/2009/2009-580-dc/version-enanglais.44721.html >. Acesso em: 29 jul. 2009.

${ }_{63}$ Daí a sigla HADOPI. O termo original, no francês, é: Haute Autorité pour la diffusion des œuvres et la protection des droits sur internet.

${ }_{64}$ FRANCÊS, Conselho Constitucional, Ibid., p. 3.

REDESG / Revista Direitos Emergentes na Sociedade Global - www.ufsm.br/redesg v. 1, n. 1, jan.jun/2012 
Direitos do Homem e do Cidadão de $1789^{65}$, que trata sobre a liberdade de expressão. 0 atual estado dos meios de comunicação implicaria, atualmente, para a liberdade de expressão, a necessidade do acesso à internet. Segundo a corte, o projeto feriria também o direito fundamental à presunção da inocência, eis que era invertido o ônus da prova, pois o internauta deveria provar sua inocência (e não o contrário). Igualmente, o bloqueio da conexão de internet não dependia de uma decisão judicial condenatória. Posteriormente a corte aprovou um substitutivo onde o bloqueio da Internet só poderia ser realizado mediante uma ordem judicial específica. Tal decisão representou um marco referencial importantíssimo no reconhecimento do acesso à internet como um direito fundamental e humano necessário para o acesso à cultura e manifestação da liberdade de expressão.

Ainda acerca da União Europeia, Temis Limberger traz o exemplo da Diretiva Comunitária n. 95/46, que trata da proteção de dados. Igualmente, a Carta dos Direitos Fundamentais da União Europeia, em seu art. $8^{\circ}$, menciona o direito à proteção de dados com o consequente aparecimento deste direito fundamental. ${ }^{66} \mathrm{~A}$ mesma diretiva citada também refere, em seu considerando n. 1, que os tratamentos de dados estão ao serviço do homem, independente de sua nacionalidade e em respeito às liberdades fundamentais.

No campo das políticas públicas que preconizam o acesso à Internet, cita-se a Diretiva 2002/22/CE do Parlamento Europeu e do Conselho, "relativa ao serviço universal e aos direitos dos utilizadores em matéria de redes e serviços de comunicações eletrônicas", que trata no seu art. $4^{\circ}$ da garantia do acesso à Internet por meio da viabilização de um acesso funcional à rede. ${ }^{67}$

Nota-se, diante de todas as normas citadas, o reconhecimento dos novos direitos - ou direitos de quinta geração - no ambiente comunitário. Esta consideração realça e evidencia também o atraso do Brasil no reconhecimento de tais direitos, em que pese o projeto do Marco Civil da Internet em avançado processo de discussão.

\subsection{Resolução das Nações Unidas sobre o assunto}

65 Ibid., p. 4.

66 LIMBERGER, Têmis. Ibid., p. 196.

67 UNIÃO EUROPEIA. Diretiva 2002/21/CE, de 7 de Março de 2002. Jornal Oficial das Comunidades Europeias. Parlamento e Conselho Europeu. Disponível em: <http://eurlex.europa.eu/LexUriServ/LexUriServ.do?uri=OJ:L:2002:108:0033:0033:PT:PDF>. Acesso em: 10 jul. 2009.

REDESG / Revista Direitos Emergentes na Sociedade Global - www.ufsm.br/redesg v. 1, n. 1, jan.jun/2012 
Tanto a ONU quanto a UNESCO possuem papel importante na definição de direitos fundamentais. Acerca dos direitos de terceira geração - ou dos direitos de solidariedade -, por exemplo, foi por meio de "sucessivas reuniões da ONU e da UNESCO bem como em documentos dessas entidades é que foram enunciados os novos direitos" ${ }^{68}$.

Em 29 de Junho de 2012 a Assembleia Geral das Nações Unidas, por intermédio do Conselho de Direitos Humanos, aprovou uma resolução para a promoção, proteção e gozo dos direitos humanos na Internet chamada de Human Rights Council Resolution on Human Rights on the Internet - A/HRC/20/L.13. ${ }^{69}$

A resolução reconhece que a liberdade de expressão na Internet é uma questão de crescente interesse e importância. Seu ponto mais importante é a afirmação de que "os mesmos direitos que as pessoas possuem 'off-line' devem também ser protegidos 'on-line', especialmente a liberdade de expressão."70

Embora a resolução destaque especificamente a liberdade de expressão, ela não exclui a proteção de outros direitos humanos. Ela amplia, como visto, o próprio alcance do art. 19 da Declaração Universal dos Direitos Humanos que prevê a questão específica da liberdade de opinião e expressão.

Por fim, a resolução destaca e reconhece o que Oliveira Júnior, já no ano de 2000, ensinava acerca dos direitos de quinta geração, conforme mencionado no capítulo 1 deste

${ }^{68}$ Cf. FERREIRA FILHO, Manoel Gonçaves. Ibid., p. 58.

69 UNITED NATIONS. The promotion, protection and enjoyment of human rights on the Internet A/HRC/20/L.13. Resolution. Disponível em: <http://daccess-ods.un.org/TMP/3228491.54472351.html>. Acesso em: 29 jun. 2012. Ela assim dispõe:

1. Affirms that the same rights that people have offline must also be protected online, in particular freedom of expression, which is applicable regardless of frontiers and through any media of one's choice, in accordance with articles 19 of the Universal Declaration of Human Rights and the International Covenant on Civil and Political Rights;

2. Recognizes the global and open nature of the Internet as a driving force in accelerating progress towards development in its various forms;

3. Calls upon all States to promote and facilitate access to the Internet and international cooperation aimed at the development of media and information and communications facilities in all countries;

4. Encourages special procedures to take these issues into account within their existing mandates, as applicable;

5. Decides to continue its consideration of the promotion, protection and enjoyment of human rights, including the right to freedom of expression, on the Internet and in other technologies, as well as of how the Internet can be an important tool for development and for exercising human rights, in accordance with its programme of work.

70 A resolução assim dispõe: "os mesmos direitos que as pessoas possuem 'off-line' devem também ser protegidos 'on-line', especialmente a liberdade de expressão, a qual é aplicável independentemente de fronteiras e através de qualquer mídia escolhida, de acordo com o artigo 19 da Declaração Universal dos Direitos Humanos e o Pacto Internacional sobre Direitos Civis e Políticos."

REDESG / Revista Direitos Emergentes na Sociedade Global - www.ufsm.br/redesg v. 1, n. 1, jan.jun/2012 
trabalho. De certa forma, a lição deste autor fica legitimada diante do avanço trazido pela referida resolução. Além do mais, mesmo que a resolução não obrigue os países signatários, indica sua intenção na proteção dos direitos de quinta geração.

\section{CONCLUSÃO}

A evolução histórica da sociedade e das novas tecnologias justifica a composição dos direitos humanos e fundamentais relacionados neste trabalho. A lição de Pierre Lévy acerca dos "três tempos do espírito", que aborda a linguagem informática como tecnologia de acesso ao conhecimento, permite que se entenda como necessária a consideração do acesso à internet e de um livre discurso na Internet como direito. Se o art. 27 da declaração Universal dos Direitos do Homem garante o "direito de participar livremente da vida cultural da comunidade" e também de "participar do progresso científico" fica claro que o acesso à internet como direito fundamental é corolário desta consideração.

A liberdade de expressão é fundamental para que seja permitida a livre manifestação do pensamento e a livre comunicação na Internet. Países que limitam a manifestação de pensamento pela Internet já se encontram desalinhados com o standard mundial de liberdade de expressão neste ambiente. Este standard é representado pelas diretivas da União Europeia que regram a proteção dos direitos fundamentais e humanos no ambiente digital bem como pela resolução da ONU sobre o assunto. É em tais marcos normativos, além da doutrina citada, que é encontrada a referência do acesso à internet como direito fundamental. É também por meio de políticas públicas de incentivo que é possível aumentar a efetividade - e concretização - do direito de acesso às novas tecnologias e também da liberdade de expressão na Internet.

Um dos pontos abordados que merece destaque diz respeito ao fato de que, com as novas tecnologias, os custos de comunicação ficam diminuídos. Qualquer usuário da Internet é um emissor-receptor de dados, informações e opiniões. Daí a importância das políticas públicas de apoio ao acesso à Internet bem como da garantia da liberdade de expressão na rede. Isto se justifica, entre outros motivos, pela ligação entre a liberdade de expressão e o direito de acesso à Internet. Se um estado ou organização limitam o acesso à Internet, este fato por si só, também tem reflexos na própria liberdade de expressão e comunicação. Em função disto, o acesso à internet deve ser entendido como um serviço universal de acordo com a Diretiva 2002/22 do Parlamento Europeu. É possível fazer uma relação, portanto, entre a universalidade do serviço 
de acesso à Internet com o baixo custo de seu uso e também com a garantia de uma qualidade mínima do serviço. ${ }^{71}$

O papel do Estado na promoção dos direitos de quinta geração é necessário, também, pela citada liderança tecnológica das grandes empresas transnacionais da Internet. Certamente, as empresas envolvidas nas relações digitais buscam o lucro - o que é legítimo - mas sem a intervenção do estado os direitos humanos podem não ser adequadamente considerados. 0 fato é que tais empresas não possuem compromisso algum com a proteção de direitos humanos na Internet, o que justifica o papel do Estado. Além do mais, a atividade dos provedores de Internet têm, na visão de Marcel Leonardi, uma importante função social. Esta função baseia-se na própria importância destas empresas na viabilização de "novas possibilidades de interação, organização e mobilização social”, o que justifica a regulação de direitos relacionados com a atividade destes intermediários. ${ }^{72}$

Um dos desafios relacionados à implementação dos direitos humanos e fundamentais de quinta geração está ligado à própria questão do espaço virtual ser desterritorializado. ${ }^{73}$ Conforme foi visto, a desterritorialização é também uma consequência do uso maciço das novas tecnologias. Diante disto, fica dificultada a atuação do Estado em certas situações uma vez que, via de regra, as leis são aplicadas dentro do espaço territorial dos Estados. No exemplo das empresas transnacionais, caso não possuam sede em um determinado Estado, a atuação deste pode ficar diminuída ou até mesmo impossível frente à violações dos direitos humanos. ${ }^{74} \mathrm{~A}$ consideração de direitos humanos fundamentais pode não ser adequadamente instrumentalizada, portanto, em função deste limite territorial.

Se Castells fala em uma sociedade em rede ou informacional ${ }^{75}$, é necessário garantir o direito das pessoas de estarem e de se manifestarem na rede. Isto, pois "nossas sociedades estão cada vez mais estruturadas em uma oposição bipolar entre a rede e o ser"76. Desta forma, sem a comunicação, surge uma alienação entre os grupos sociais. Esta alienação é dissipada com a consideração do acesso à internet como direito fundamental. Mas não é o suficiente. É

71 Esta qualidade abrange também uma velocidade mínima para o uso da Internet. Atualmente é comum que os internautas acessem vídeos e outros conteúdos de natureza multimídia, o que enseja alto fluxo de dados. Desta forma, o acesso à Internet de baixa velocidade pode impedir o acesso a tais conteúdos.

72 LEONARDI, Marcel. Ibid., p. 109.

73 LORENZETTI, Ricardo L.. Comércio Eletrônico. São Paulo: Revista dos Tribunais, 2004, p. 29.

74 LÉVY, Pierre. Cibercultura. São Paulo: Ed. 34, 1999, p. 204. O autor afirma, no mesmo trecho, também que: "O Estado perde, assim, o controle sobre uma parte cada vez mais importante dos fluxos econômicos e informacionais transfronteiriços"

75 CASTELLS, Manuel. Ibid., p. 50.

76 Ibid., p. 41.

REDESG / Revista Direitos Emergentes na Sociedade Global - www.ufsm.br/redesg v. 1, n. 1, jan.jun/2012 
necessário envolver também políticas públicas de educação digital permitindo que as pessoas consigam saber utilizar os meios tecnológicos. A própria educação básica precisa compreender a educação digital para permitir o pleno desenvolvimento humano com o uso das novas tecnologias.

A proteção do livre discurso na rede e do acesso à internet como direitos fundamentais garante a preservação do próprio princípio da dignidade de pessoa humana em tal ambiente. Além do mais, preserva a Internet como uma grande conquista tecnológica da humanidade baseada, como se sabe, na liberdade dos fluxos de comunicação.

Já no Brasil, o Marco Civil da Internet parece dar um passo importantíssimo para a instrumentalização e concretização dos “novos direitos” até aqui referidos. Há, de fato, uma insegurança jurídica baseada na inexistência de um dispositivo legal específico no reconhecimento e tutela de direitos na Internet, principalmente acerca dos direitos humanos relacionados com seu uso. O Marco Civil, portanto, tem o condão de afastar a insegurança jurídica nesta matéria.

Por fim, diante de todo o exposto, adota-se a recomendação de Lorenzetti, que traz como possível solução para a adequada proteção de tais direitos a utilização de normas de fontes comunitárias ou tratados internacionais ${ }^{77}$ na esteira das citadas diretivas da União Europeia. Desta forma, a recente resolução das Nações Unidas sobre o assunto direciona as nações signatárias para este caminho.

\section{REFERÊNCIAS}

$1^{\text {st }}$. COUNCIL OF EUROPE CONFERECE OF MINISTERS RESPONSIBLE FOR MEDIA AND NEW COMUNICATION SERVICES. Political declaration and resolutions. 28 e 29 may 2009. Disponível em: <http://www.ministerialconference.is/media/images/MCM2009011_en_final_web.pdf>. Acesso em: 12 jul. 2009.

AKDENIZ, Yaman. To block or not to block: European approaches to content regulation, and implications for freedom of expression. Computer Law \& Security Review, v. 26, n. 3, p. 260272, 2010. Elsevier Ltd. Disponível em: <http://linkinghub.elsevier.com/retrieve/pii/S0267364910000518>. Acesso em: 17 Jul. 2012

ALEXY, Robert. Teoria de los derechos fundamentales. Trad. VALDÉS, Ernesto Garzón. Madrid: Centro de Estudios Constitucionales, 1993.

77 LORENZETTI, Ricardo L.. Ibid., p. 89.

REDESG / Revista Direitos Emergentes na Sociedade Global - www.ufsm.br/redesg v. 1, n. 1, jan.jun/2012 
ANTUNES, Ruy Barbedo. Direitos fundamentais e direitos humanos: a questão relacional. Revista da Escola de Direito de Pelotas. v. 6 (1), Jan.-Dez./2005. p. 331-356.

BALKIN, Jack M..Digital Speech and Democratic Culture: a Theory of Freedom of Expression for the Information Society. New York University Law Review, Vol. 79, No. 1, 2004. N. 63. Disponível em: <http://ssrn.com/abstract=470842 or DOI: 10.2139/ssrn.470842>. Acesso em: 05 jun. de 2009

BAUMAN, Zygmunt. Tempos Líquidos. Rio de Janeiro: Jorge Zahar, 2007.

CANOTILHO, José Joaquim Gomes. Direito Constitucional. 6. ed. Coimbra: Almedina, 1993.

CASTELLS, Manuel. A sociedade em rede. $6^{\text {a }}$ ed. São Paulo: Paz e Terra, 1999.

CHANDER, Anupam. Whose Republic? University of Chicago Law Review, vol. 69, n. 3, p. 14801500. 2002. Disponível em: <http://ssrn.com/abstract=417600>. Acesso em: 12 jan. 2012.

DA SILVA, Regina Beatriz Tavares. Sistema protetivo dos direitos da personalidade. In: DA SILVA, Regina Beatriz Tavares; DOS SANTOS, Manoel J. Pereira (coord.). Responsabilidade Civil na Internet e nos demais Meios de Comunicação. São Paulo: Saraiva, 2007, capítulo I.

DEVA, Surya. Corporate Complicity in Internet Censorship in China: Who Cares for the Global Compact or the Global Online Freedom Act? George Washington International Law Review, Vol. 39, p. 255-319, 2007. Disponível em <SSRN: http://ssrn.com/abstract=964478>. Acesso em: 14 mai. 2009.

FERREIRA FILHO, Manoel Gonçalves. Direitos humanos fundamentais. 3. ed. São Paulo: Saraiva, 1999.

FRANCÊS, Conselho Constitucional. Partes: M. Jean-Marc AYRAULT et al., Decisão ${ }^{\circ}$ 2009-580 de 10 de Junho de 2009. Disponível em <http://www.conseil-constitutionnel.fr/conseilconstitutionnel/francais/les-decisions/2009/decisions-par-date/2009/2009-580-dc/version-enanglais.44721.html>. Acesso em: 29 jul. 2009.

HARTMANN, Ivan Alberto Martins. 0 acesso à internet como direito fundamental. 2007. $94 \mathrm{f}$. Orientador SARLET, Ingo Wolfgang. Monografia (Bacharelado em Ciências Jurídicas e Sociais). Pontifícia Universidade Católica do Rio Grande do Sul, Porto Alegre, 2007.

JAYME, Erik. Identité culturelle et intégration: Le droit internationale privé postmoderne. Cours général de droit international privé. Recueil des cours de l'Académie de Droit International de la Haye. Hague, v. 251, 1996.

LEITE, Carlos Henrique Bezerra. As três dimensões dos direitos humanos e o novo conceito de cidadania. Revista do Tribunal Regional do Trabalho da $13^{\text {a }}$ Região, João Pessoa, v. 12, n. 9 , p. 104-108, 2004. Disponível em: <http://www.trt13.jus.br/ejud/images/revistasdigitais/revista12_trt13.pdf>. Acesso em: 29 set. 2008. 
LEONARDI, Marcel. Tutela e privacidade na Internet. São Paulo: Saraiva. 2012.

- Internet e regulação: o bom exemplo do Marco Civil da Internet. Revista do

Advogado, São Paulo, n. 115, ano XXXII, p. 99-112, abr. 2012.

LÉVY, Pierre. As tecnologias da inteligência. Rio de Janeiro: Editora 34, 1993.

LIMBERGER, Têmis. Direito e informática: o desafio de proteger os direitos do cidadão. In SARLET, Ingo. Wolfgang (org). Direitos Fundamentais, Informática e Comunicação: algumas aproximações. Porto Alegre: Livraria do Advogado, 2007. p. 195 a 226.

LORENZETTI, Ricardo L.. Comércio Eletrônico. São Paulo: Editora Revista dos Tribunais, 2004.

LYOTARD, Jean-Francois. O pós-moderno. Rio de Janeiro: José Olympio, 1986.

MICHELMAN, Frank I.. Relações entre democracia e liberdade de expressão: discussão de alguns argumentos . In SARLET, Ingo. Wolfgang (org). Direitos Fundamentais, Informática e Comunicação: algumas aproximações. Porto Alegre: Livraria do Advogado, 2007. p. 49-62.

NEVES, Marcelo. Transconstitucionalismo. São Paulo: Martins Fontes, 2009

OLIVEIRA JÚNIOR, José Alcebíades de. Teoria Jurídica e Novos Direitos. Rio de Janeiro: Lumen Juris, 2000.

. Cultura democrática para direitos humanos multiculturais. In Revista Estudos

Jurídicos. V. 40 (2). jul. - dez. 2007. São Leopoldo. Unisinos. Disponível em

<http://www.unisinos.br/publicacoes_cientificas/images/stories/Publicacoes/estudos_juridicos vol40n2/79a83_art05_oliveira_junior\%5Brev_ok\%5D.pdf>. Acesso em: 14 jun. 2009.

PASOLD, Cesar Luiz. Novos Direitos: conceitos operacionais de cinco categorias que lhes são conexas. Revista Sequência, n. 50, jul. De 2005, p. 225-236

PEREIRA, Julia Lafayette; ROTT, Rafael; SALDANHA, Jânia Maria Lopes Saldanha. A efetividade dos direitos humanos de terceira geração: a análise de um caso venezuelano. Revista Eletrônica do Curso de Direito da UFSM. vol. 2, n. 3, Novembro de 2007. Disponível em

<http://www.ufsm.br/revistadireito/v2n3.html>. Acesso em: 29 jul. 2009.

ROHRMANN, Carlos Alberto. Curso de Direito Virtual. Belo Horizonte: Del Rey, 2005.

SANTOS, Boaventura de Sousa. Os direitos humanos na pós-modernidade. Oficina do CES Centro de Estudos Sociais, Coimbra, n. 10, Junho de 1989.

. Para uma Concepção Multicultural dos Direitos Humanos. Contexto Internacional, Rio de Janeiro, vol. 23, n 1, p. 7-34, jan/jun 2001.

UNIÃO EUROPEIA. Diretiva 95/46/CE, de 24 de Outubro de 1995. Jornal Oficial das

Comunidades Europeias. Parlamento e Conselho Europeu. Disponível em: <http://eur- 
lex.europa.eu/LexUriServ/LexUriServ.do?uri=CELEX:31995L0046:PT:HTML>. Acesso em: 10 jul. 2009.

. Diretiva 2000/31/CE, de 8 de Junho de 2000. Jornal Oficial das Comunidades

Europeias. Parlamento e Conselho Europeu. Disponível em: <http://eur-

lex.europa.eu/LexUriServ/LexUriServ.do?uri=OJ:L:2000:178:0001:0016:PT:PDF>. Acesso em: 10 jul. 2009.

. Diretiva 2002/21/CE, de 7 de Março de 2002. Jornal Oficial das Comunidades

Europeias. Parlamento e Conselho Europeu. Disponível em: <http://eur-

lex.europa.eu/LexUriServ/LexUriServ.do?uri=OJ:L:2002:108:0033:0033:PT:PDF>. Acesso em:10 jul. 2009.

UNITED NATIONS. Report of the Special Rapporteur on the promotion and protection of the right to freedom of opinion and expression - A/HRC/17/27. Report . Disponível em: <http://www.unhcr.org/refworld/docid/49f8416d2.htm>. Acesso em: 10 jun. 2012.

. The promotion, protection and enjoyment of human rights on the Internet A/HRC/20/L.13. Resolution. Disponível em: <http://daccess-

ods.un.org/TMP/3228491.54472351.html>. Acesso em: 29 jun. 2012.

VELOSO, Elisabeth Machado. Legislação sobre internet no Brasil. Brasilia: Câmara dos Deputados, 2009. 54p. Disponível em: www.fndc.org.br/arquivos/Regulacao_internet.pdf. Acesso em: 29 jul. 2009.

Recebido em: 27.07.2012 / Aprovado em: 04.09.2012 